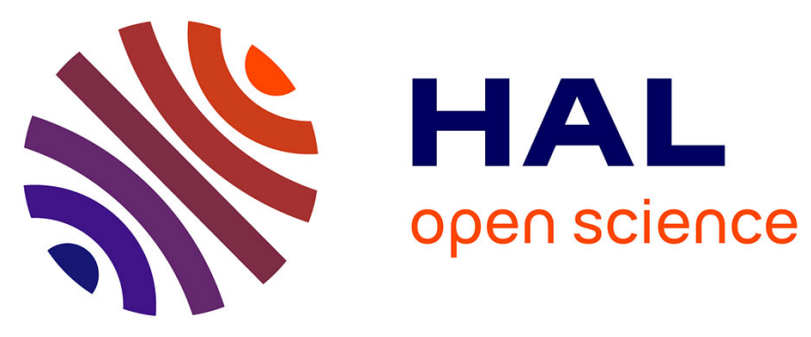

\title{
On the Detection Capabilities of Underwater Distributed Acoustic Sensing
}

Itzhak Lior, Anthony Sladen, Diane Rivet, Jean-Paul Ampuero, Yann Hello, Carlos Becerril, Hugo F. Martins, Patrick Lamare, Camille Jestin, Stavroula Tsagkli, et al.

\section{To cite this version:}

Itzhak Lior, Anthony Sladen, Diane Rivet, Jean-Paul Ampuero, Yann Hello, et al.. On the Detection Capabilities of Underwater Distributed Acoustic Sensing. Journal of Geophysical Research: Solid Earth, 2021, 126 (3), pp.e2020JB020925. 10.1029/2020jb020925 . hal-03229358v2

\section{HAL Id: hal-03229358 https://hal.science/hal-03229358v2}

Submitted on 29 Nov 2021

HAL is a multi-disciplinary open access archive for the deposit and dissemination of scientific research documents, whether they are published or not. The documents may come from teaching and research institutions in France or abroad, or from public or private research centers.
L'archive ouverte pluridisciplinaire HAL, est destinée au dépôt et à la diffusion de documents scientifiques de niveau recherche, publiés ou non, émanant des établissements d'enseignement et de recherche français ou étrangers, des laboratoires publics ou privés. 


\section{On the Detection Capabilities of Underwater DAS}

Itzhak Lior ${ }^{1}$, Anthony Sladen ${ }^{1}$, Diane Rivet ${ }^{1}$, Jean-Paul Ampuero ${ }^{1}$, Yann Hello ${ }^{1}$, Patrick Lamare ${ }^{2}$, Camille Jestin ${ }^{3}$, Stavroula tsagkli4 and Christos Markou ${ }^{4}$.

1Université Côte d'Azur, CNRS, Observatoire de la Côte d'Azur, IRD, Géoazur ${ }^{2}$ Aix Marseille Université, CNRS/IN2P3, CPPM

${ }^{3}$ Febus-optics, Pau, France

${ }^{4}$ NCSR Demokritos, Institute of Nuclear and Particle Physics, Ag. Paraskevi Attikis, Athens, Greece

Corresponding author: Itzhak Lior (itzhaklior22@gmail.com)

\section{Key Points:}

- The noise content of underwater DAS along three different telecommunication cables is quantified and compared to adjacent broadband stations.

- Earthquake detection capabilities using DAS are similar to those of broadband instruments.

- Detection capabilities are mainly a function of the recorded noise, cable response and apparent velocity. 


\section{Abstract}

The novel technique of distributed acoustic sensing (DAS) holds great potential for underwater seismology by transforming standard telecommunication cables, such as those currently traversing most of the world's oceans, into dense arrays of seismo-acoustic sensors. To harness these measurements for seismic monitoring, the ability to record transient ground deformations using telecommunication fibers is investigated here by analyzing ambient noise, earthquake signals, and their associated phase velocities, on DAS records from three dark fibers in the Mediterranean Sea. The recording quality varies dramatically along the fibers and is strongly correlated with the bathymetry and the apparent phase velocities of the recorded waves. Apparent velocities are determined for several wellrecorded earthquakes and used to convert DAS S-wave strain spectra to ground motion spectra. Excellent agreement is found between the spectra of nearby underwater and on-land seismometers and DAS converted spectra, when the latter are corrected for site effects. Apparent velocities greatly affect the ability to detect seismic deformations: for the same ground motions, slower waves induce higher strains and thus are more favorably detected than fast waves. The effect of apparent velocity on the ability to detect seismic phases, quantified by expected signal-to-noise ratios, is investigated by comparing signal amplitudes predicted by an earthquake ground motion model to recorded noise levels. DAS detection capabilities on underwater fibers are found to be similar to those of nearby broadband sensors, and superior to those of on-land fiber segments. The results demonstrate the great potential of underwater DAS for seismic monitoring and earthquake early warning.

\section{Introduction}

To date, most observational earthquake research relies on ground motions recorded by seismometers. These instruments are typically installed in proximity to active faults, as the most valuable observations are those obtained very close to earthquake epicenters: they provide the most coherent view of source processes and allow for early detection of large earthquakes and monitoring of small ones. However, there is a severe observational gap: the vast majority of seismometers are located on-land, while the largest earthquakes, and most tsunami generating earthquakes, occur underwater. Existing technologies to overcome this observational gap, e.g., ocean-bottom seismometers (OBS), are very costly and thus not widely implemented. The lacking ocean-bottom monitoring hinders the ability to conduct underwater seismological research. This is especially critical for hazard mitigation tasks such as providing earthquake early warning (EEW) (e.g., Allen and Melgar, 2019; Lior and Ziv, 2020; Vallée et al., 2017) for underwater earthquakes, since precious time is lost waiting for seismic signals to reach on-land stations. Filling this underwater observational gap 
will greatly benefit hazard mitigation capabilities and constitute a major step forward in seismological research.

In recent years, the innovative approach of distributed acoustic sensing (DAS) is being used for many seismological tasks (Zhan, 2019, and reference therein). DAS enables the measurement of transient ground deformations along standard optical fibers such as those inside the telecommunication cables currently traversing most of the world's oceans. Implementing DAS technology on available underwater fibers has great potential to fill the underwater observational gap. The ability to record and analyze earthquakes using underwater DAS has been recently demonstrated (Sladen et al., 2019; Lindsey et al., 2019; Williams et al., 2019), but is yet to be fully realized. To reliably harness this technique for earthquake monitoring, the nature of underwater DAS measurements needs to be better understood.

In a previous study, Sladen et al. (2019) used an underwater optical fiber offshore Toulon, South of France, and showed that uneven cable-ground coupling and water-Earth interactions significantly affect the sensitivity to ground motions thus limiting the reliability of earthquake monitoring on underwater telecommunication fibers. Because these underwater cables were installed for the sole purpose of power and data transmission between two points in space, the mechanical coupling between the cable and the ocean-bottom is not uniform along the fiber. This reduces the cable's recording quality to a point that the coupling of several cable segments is insufficient for seismic measurements. The studies by Lindsey et al. (2019) and Willams et al. (2019) relied on seafloor buried cables, which reduced many of these problems, but buried cables are just a small fraction of the global network of seafloor cables. Sladen et al. (2019) also found that underwater DAS earthquake recordings are dominated by Scholte-waves, indicating that acoustic and seismic waves are converted and scattered at the ocean - solid-earth interface. Moreover, interactions between the watercolumn and solid-earth generate several noise sources, i.e., gravity waves and microseisms, which constitute coherent noise that could affect earthquake monitoring with underwater DAS measurements.

Fully unlocking the potential of underwater DAS will facilitate the use of optical fibers as next-generation dense seismic networks, overcoming the disadvantages of discrete, mainly on-land, seismic sensors, thus filling a vast observational gap. A significant first step, is to understand and quantify earthquake detection and measurement abilities and set detection thresholds by characterizing measured noise, seismic signals, and their relation to ground motions. To this end, underwater DAS noise and seismic signals are analyzed here using data recorded by three different underwater DAS fibers, one in France and two in Greece. DAS records are then compared to those of nearby broadband stations, two of which are located underwater. 
This manuscript is organized as follows. In the next section, the dataset used for this study is described. Then, underwater DAS noise is characterized by computing noise power spectral densities (PSDs). In section 4 , several cataloged earthquakes are used to analyze the response of the different fibers to ground deformation and the conversion from DAS recorded strain to ground motions. Finally, implications for DAS detection capabilities are discussed.

\section{Data}

This study uses an extensive dataset of underwater DAS records, acquired by Géoazur, from three underwater cables: two offshore Methoni, south-west Greece, and one offshore Toulon, South of France. In addition, data from 4 on-land and 2 underwater broadband stations, installed near the cables, are used. The cables' locations, depth profiles, and broadband station locations are shown in Figure 1. Because these cables were simply deployed to provide communication between the two ends of the fiber, the cables' exact geographical position and bathymetric profiles are not well constrained. All cables recorded several local earthquakes during the measurement campaigns; those analyzed in the next sections are indicated in Figure 1 and listed in Table 1. Here, the cables and instrumental setup are described.

DAS data from Greece were acquired on two adjacent dark optical fibers, situated on the Central Hellenic Shear Zone, near a triple junction: the Kephalonia Transform Fault to the north-west, and the Hellenic Trench and Mediterranean Ridge to the south-east (Finetti, 1982). These cables are intended for the HCMR (Hellenic Centre for Marine Research) and NESTOR (Neutrino Extended Submarine Telescope with Oceanographic Research) (Aggouras et al., 2005; Anassontzis and Koske, 2003) projects. DAS data were acquired on April 18th and 19th 2019 on the HCMR cable and from April 19th to 25 th on the NESTOR cable. The HCMR and NESTOR cables span 13.2 and $26.2 \mathrm{~km}$, respectively: from a common landing point, they traverse the shallow Methoni bay and then diverge in different directions towards the bottom of the East Ionian Sea (Figure 1). These cables were interrogated using an old generation Febus Al DAS interrogator, developed by Febus Optics. The gauge length and spatial sampling were set to 19.2 meters for

\begin{tabular}{|c|l|l|l|l|}
\hline $\begin{array}{c}\text { Cable } \\
\text { name }\end{array}$ & \multicolumn{1}{|c|}{ Origin time } & Magnitude & $\begin{array}{c}\text { Location (latitude, } \\
\text { longitude, depth[km]) }\end{array}$ & \multicolumn{1}{c|}{ catalog } \\
\hline \multirow{4}{*}{ NESTOR } & $22 / 04 / 201919: 26: 06$ & 3.3 & $37.4185,20.6897,11.0$ & Athens University \\
\cline { 2 - 6 } & $23 / 04 / 201917: 29: 40$ & 3.6 & $37.7753,20.7658,7.0$ & Athens University \\
\cline { 2 - 6 } & $21 / 04 / 201922: 11: 47$ & 2.0 & $36.8335,22.0382,2.0$ & Athens University \\
\cline { 2 - 6 } & $23 / 04 / 201919: 25: 51$ & 2.6 & $37.2528,21.4593,9.0$ & Athens University \\
\hline \multirow{2}{*}{ HCMR } & $18 / 04 / 201921: 44: 42$ & 3.7 & $37.57,20.66,8.0$ & EMSC \\
\cline { 2 - 6 } & $19 / 04 / 201903: 30: 19$ & 2.6 & $37.1523,20.6662,1.0$ & Athens University \\
\hline \multirow{2}{*}{ MEUST } & $19 / 07 / 201921: 16: 57$ & 2.6 & $44.374,6.913,2.6$ & Géoazur \\
\cline { 2 - 6 } & $21 / 07 / 201923: 01: 58$ & 2.4 & $42.516,5.143,2.0$ & Géoazur \\
\hline
\end{tabular}

Table 1: earthquakes used in this study. 
manuscript submitted to Journal of Geophysical Research: Solid Earth

141

142

143

144

145

146

147

both cables, equivalent to 688 and 1365 channels of strain-rate equally spaced along the HCMR and NESTOR cables, respectively. Strain-rate was sampled at intervals of 6 milliseconds for HCMR and 5 milliseconds for NESTOR, producing 68 GB and 740 GB of data for HCMR and NESTOR, respectively. In addition to DAS data, several broadband seismometers were available during these DAS measurements: two on-land, deployed near the interrogator for the duration of the measurements, and one permanent OBS

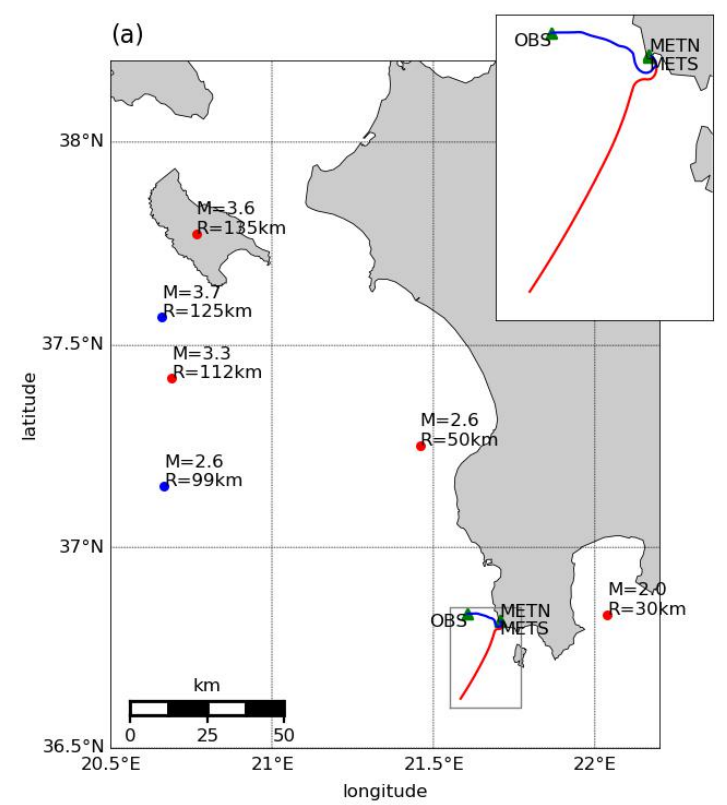

(c)

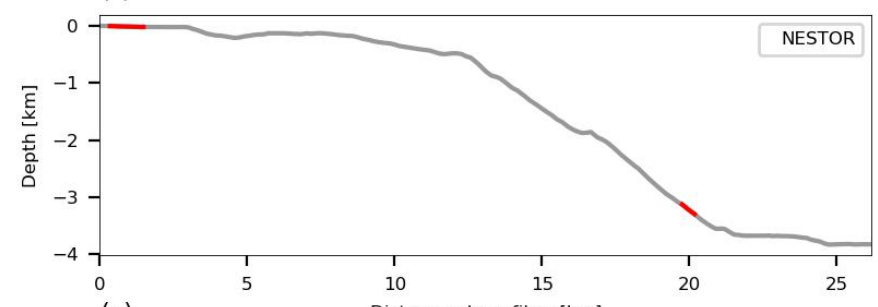

(e)

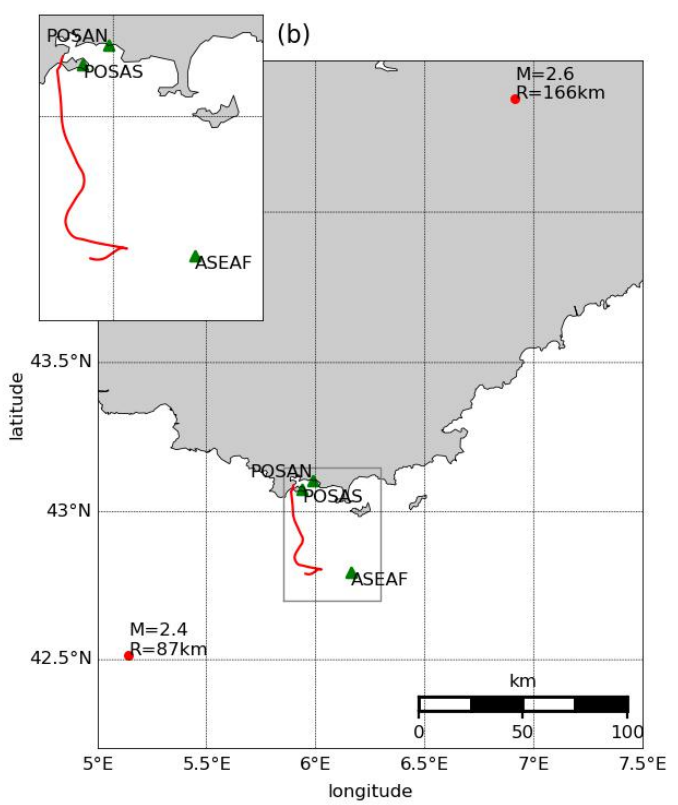

(d)

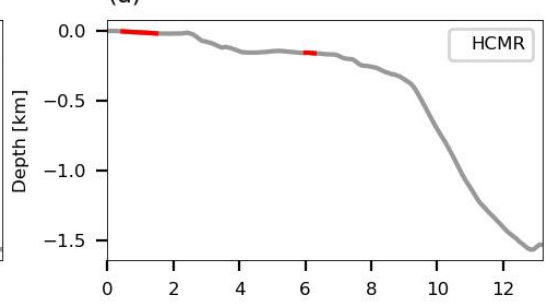

Distance along fiber [ $\mathrm{km}]$

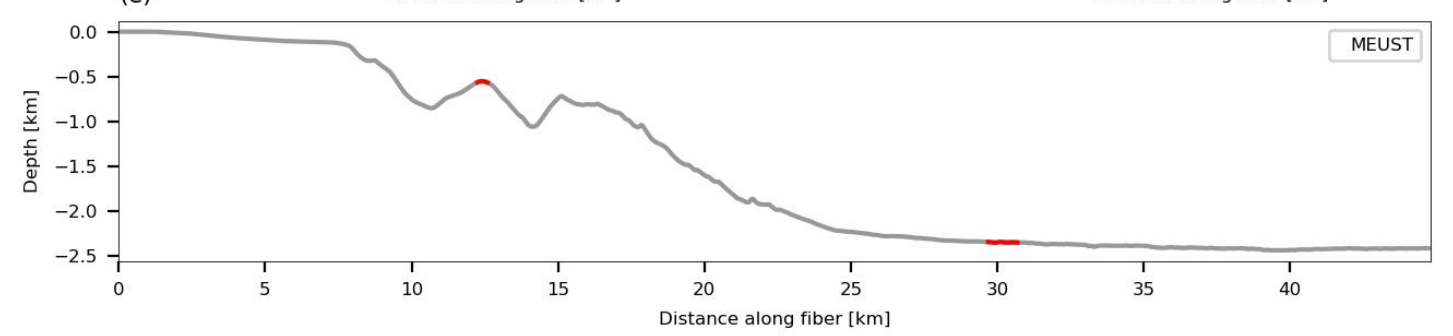

Figure 1: Maps of Methoni and Toulon regions along with cable depth profiles. map of the a) Methoni and b) Toulon regions along with cable locations, broadband stations and analyzed earthquakes. The HCMR, NESTOR and MEUST cables, along with their recorded earthquakes, are indicated in red and blue (left panel), and red (right panel), respectively. Insets correspond to regions marked by gray rectangles. Cable depth profiles are shown in panels (c-e). Sections used in subsequent analysis are indicated in red. 
near the end of the HCMR cable. Calibration information for the latter, a Guralp CMG40T, was unavailable. The flat frequency response of this sensor, between 30 seconds and $50 \mathrm{~Hz}$, includes the recorded seismic signals, thus, a simple empirical response was estimated by comparing available earthquake records between the OBS and the on-land sensors.

The offshore Toulon data were acquired on the same fiber used by Sladen et al. (2019), between July 11th and 31st 2019. The path of this fiber was slightly modified in October 2018, after a first DAS acquisition done by Sladen et al. (2019) (Figure 1). This cable is located in an area of moderate seismicity and is used for the MEUST-NUMerEnv project (Mediterranean Eurocentre for Underwater Sciences and Technologies - Neutrino Mer Environnement) (Lamare, 2016). The cable spans $44.8 \mathrm{~km}$ : from the coast to the deep Mediterranean plain. For this cable, an hDAS interrogator (HighFidelity Distributed Acoustic Sensor), developed by Aragon Photonics, was used, which produces strain measurements. The gauge length and spatial sampling were set to 10 meters, equivalent to 4480 equally spaced channels of strain measured along the cable. Sampling intervals were set to 10 and 2 milliseconds for the first and last 10 days of the campaign, respectively, producing 16 TB of data. In addition, 2 on-land broadband sensors, installed near the interrogator, were used. The OBS near the end of the fiber (ASEAF station) was inactive during this measurement campaign, but OBS records from July 2017 were used for noise analysis. These were obtained at a similar time of year, and represent equivalent water temperature $\left(23-24{ }^{\circ} \mathrm{C}\right)$ and wave height conditions, as obtained from the Coriolis database (coriolis.eu.org).

\section{DAS Noise Analysis}

The recorded DAS noise arises from several natural sources, including ocean-solid earth interactions, which produce gravity waves and microseisms. The natural noise amplitude can be affected by local seismic amplification effects. In addition, ground-cable coupling variations modulate the recorded noise and signals, and instrumental noise dominates several frequencybands along the fibers. In this section, underwater DAS noise is analyzed and quantified.

The noise content of underwater DAS records and broadband sensors is quantified by computing PSDs. These PSDs were calculated for the full duration of each campaign at every measurement point along the fibers, following the procedure described in McNamara and Buland (2004). PSDs for the OBS at the end of the HCMR cable were not computed due to missing instrumental response. Because seismic noise PSDs are typically obtained for ground motion accelerations (McNamara and Buland, 2004), here they are calculated for strain-rate; the transition between acceleration and strain-rate, though not straightforward (section 4.2), facilitates a comparison between both measures. While HCMR and NESTOR records were acquired in strainrate, MEUST strain records were differentiated to strain-rate in the 
frequency-domain. The PSDs, averaged per measurement location along the fiber, are plotted in Figure 2 as functions of frequency and distance from the interrogator along the fiber. PSDs for selected locations along the cables, as well as for the broadband sensors, are plotted in Figure 3. The various noise sources shown in Figures 2 and 3 are further described.

Solid-earth - ocean-bottom interactions generate several noise sources, recorded by the fibers. At shallow water depths, DAS records are dominated by surface gravity waves at frequencies of 0.05 to $0.3 \mathrm{~Hz}$ (black curves in Figure 2 and panels a and c of Figure 3). The dominant frequency of these

(a)

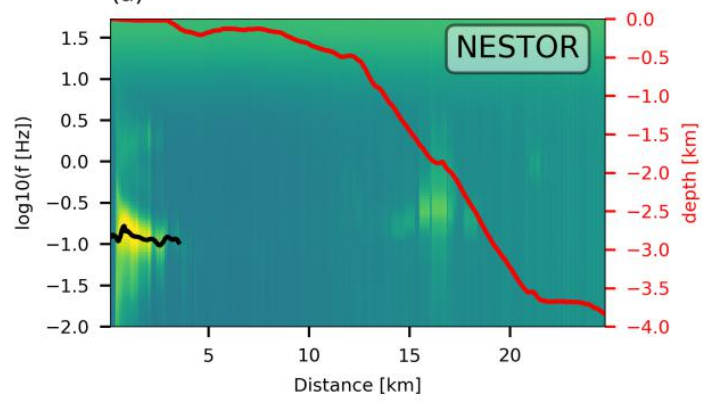

(c)

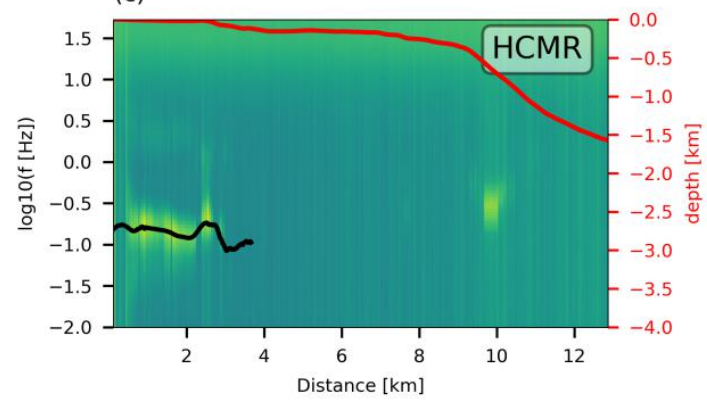

(e)

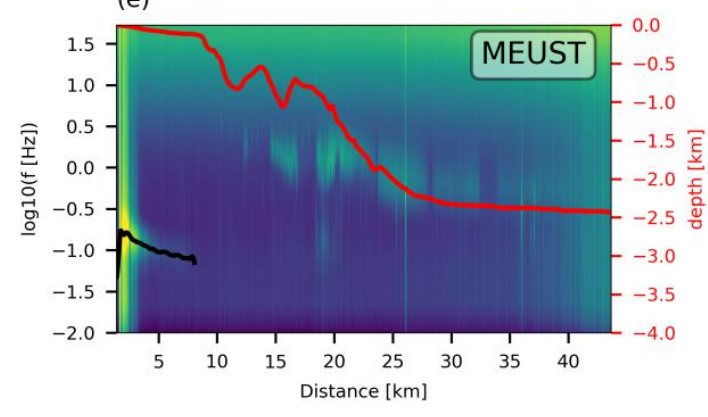

(b)

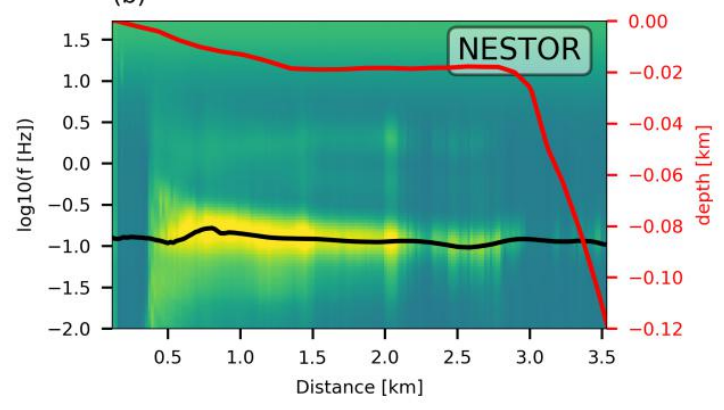

(d)

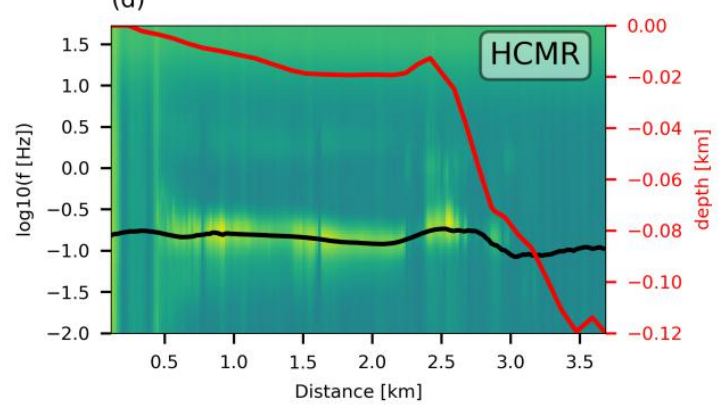

(f)

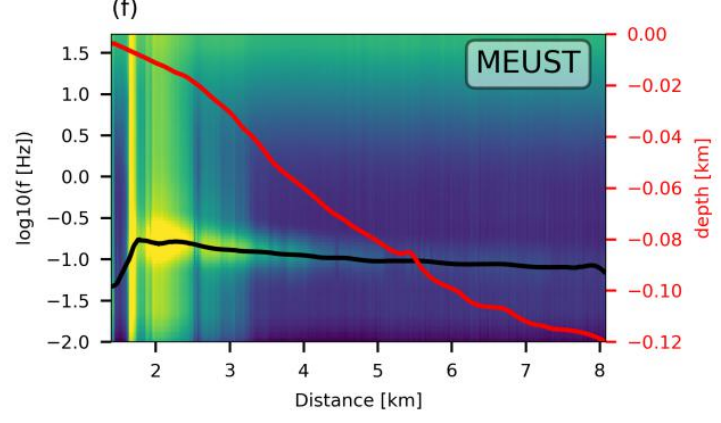

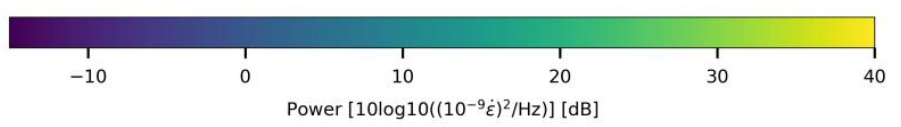

Figure 2: Noise analysis for the 3 cables: average nano-strain-rate PSD as a function of frequency and distance along the fibers. Left panels show the full cable and right panels show the cable up to a water depth of $120 \mathrm{~m}$. Red line indicates bathymetric profiles (right axis), and black lines indicate the peak frequency of gravity waves (frequency associated with the maximum PSD). 
manuscript submitted to Journal of Geophysical Research: Solid Earth

waves decreases with increasing water depth (red curves in Figure 2) as predicted by the dispersion relation of surface gravity waves. This effect is also seen in the comparison of HCMR and NESTOR PSDs at 1 and $2 \mathrm{~km}$ depths (Figure 3a). Surface gravity wave amplitudes are in close agreement for
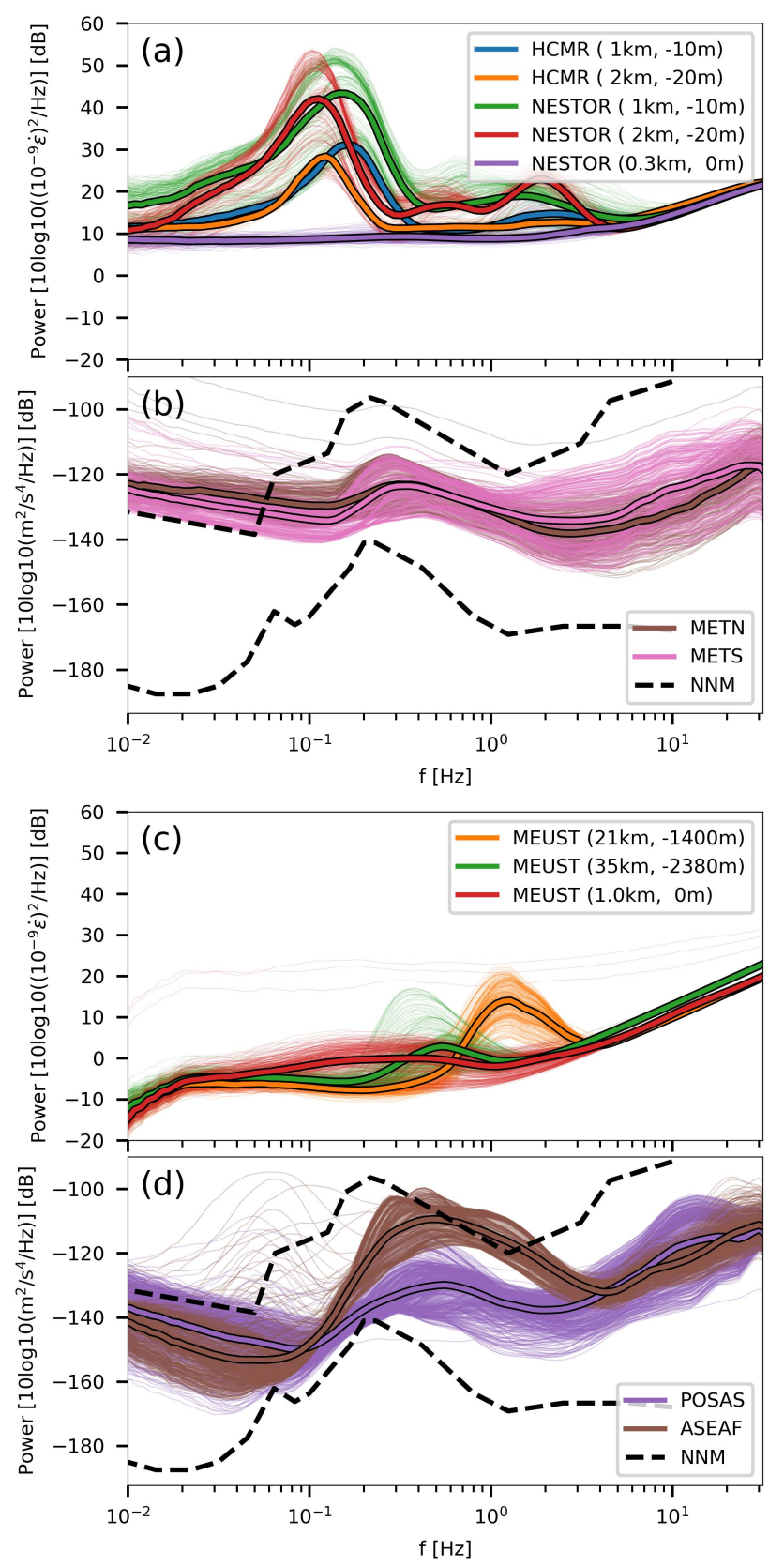

Figure 3: Comparison of DAS (panels $a$ and $c$ ) and broadband (panels $b$ and d) PSD. DAS PSDs are displayed for specific distances from the interrogator and water depths as indicated in the panel legends. NESTOR PSD at $0.3 \mathrm{~km}$ and MEUST PSD at $1 \mathrm{~km}$ correspond to on-land cable segments. Thin and thick lines represent one hour PSD and an average of all available one hour PSDs. The new low and high noise models (Peterson, 1993) are indicated in dashed black lines for broadband data (panels $b$ and $d$ ). 
NESTOR and MEUST in-spite of the different regions and interrogators (panels $b$ and $f$ of Figure 2 and panels $a$ and $c$ of Figure 3), while those recorded by HCMR are slightly lower. The disparity between gravity wave amplitudes obtained by NESTOR and HCMR, both recorded in Methoni bay, indicate that they are affected by local meteorological conditions: during the NESTOR measurements a storm occurred, inducing higher amplitude gravity waves.

HCMR and NESTOR exhibit an additional signature at frequencies of 1 to $2 \mathrm{~Hz}$. This signal is a local effect, only observed on cable sections inside Methoni bay, and thus likely related to the seismic response of a sedimentary basin. Full analysis of this signal is beyond the scope of this manuscript, yet its effect on earthquake ground deformations is further described in section 5 .

Short fiber stretches are deployed on-land between the DAS interrogators' locations and the shorelines. These extra lengths of fiber provide an opportunity to compare the characteristic noise levels on-land and underwater. The PSDs for NESTOR and MEUST, shown in Figure 3 (panels $a$ and $c$ ), indicate lower noise levels than those of underwater segments. However, these short on-land segments, do not record any seismic signals, as further discussed in section 5 .

At deeper sections, typically deeper than 2000 meters, the MEUST cable records secondary microseisms, as previously observed by Sladen et al. (2019). These microseisms appear at frequencies of 0.3 to $3 \mathrm{~Hz}$ and are the result of interference between ocean waves traveling in opposite directions (Longuet-Higgins, 1950). Similar to gravity waves, secondary microseisms exhibit a frequency decrease with increasing water depth as shown in Figure $2 \mathrm{e}$ and $3 \mathrm{c}$. The peak frequency recorded at the end of the MEUST cable (green curve in Figure $3 \mathrm{c}$ ) matches that observed by the nearby ASEAF OBS (purple curve in Figure 3d).

In addition to natural noise sources, instrumental effects are apparent in Figures 2 and 3. In several frequency bands and distances along the fibers, instrument (interrogator and fiber) related noise dominates the PSDs (Figures 2 and 3). These are slightly higher for the old generation interrogator (used in HCMR and NESTOR) than for the new generation one (used in MEUST), and higher for high frequencies than low frequencies (Fernández-Ruiz et al., 2019). Noise levels have spatial fluctuations along the fibers that are persistent in time and similar for different frequencies, as demonstrated in Figure S1, where average PSDs are plotted for a section of MEUST. Even though the amplitude and distance scales of the fluctuations could be consistent with those observed for fading (e.g., Gabai and Eyal, 2016; Martins et al., 2013), it is not plausible that fading patterns persist for more than several seconds (analyzed PSDs are averaged over many hours). These small fluctuations (typically less than $2 \mathrm{~dB}$ ) may be a result of the fibers' backscattering pattern, which is known to affect high-frequency noise 
in chirped-pulse interrogators (Costa et al., 2019), yet further research is needed to understand it over a broader frequency band and for other interrogator types.

Since the used cables were deployed over seldom irregular bathymetry (Figure 1), their ocean-bottom - cable coupling is nonuniform along the cables. This results in gaps in the measurements of coherent signals: gravity waves, microseism signals (Figure 2), and earthquakes (section 4). In addition, several fiber segments display oscillating patterns, as seen in Figure 2 (e.g., between 12 and $17 \mathrm{~km}$ for NESTOR in panel a), which may be related to the fibers' layout, e.g., high tension segments, cables hanging over seafloor valleys. These patterns will require additional research, possibly involving direct inspections of the cable for validation.

Finally, broadband seismometers' noise (panels $b$ and d of Figure 3) are mostly within the limits of the new low/high noise models (NLNM and NHNM) of Peterson (1993). Expected exceptions are the slightly higher low frequency noise, resulting from the proximity of the stations to the Mediterranean basin (e.g., De Caro et al., 2014), and the high amplitude second microseism peak observed for the ASEAF OBS.

The described natural and instrumental noise sources affect earthquake detection and analysis abilities as detailed in following sections. Next, underwater DAS earthquake signals are analyzed and their interactions with observed noise are discussed.

\section{DAS Earthquake Signals}

Here, the ability to record earthquakes by underwater DAS, and the response of the different cables to transient ground motions are investigated. Then, apparent velocities are inferred and strain-rate measurements are converted to ground motion accelerations and compared with records of adjacent broadband sensors. To this end, several cataloged earthquakes are analyzed: 2 earthquakes recorded by HCMR, 4 earthquakes recorded by NESTOR, and 2 earthquakes recorded by MEUST. Earthquake locations and magnitudes were taken from one of the available catalogs: EuropeanMediterranean Seismological Centre (EMSC), University of Athens, or Géoazur catalogs. The earthquake data is summarized in Table 1 and locations, magnitudes and distances to the interrogators appear in Figure 1.

\subsection{Cable Response}

The response of underwater telecommunication fibers to transient deformations is non-uniform; recorded earthquake signals vary in amplitude 
and frequency content along the cable. This is clearly seen in Figure 4 for a magnitude 3.7 earthquake recorded on the HCMR cable (equivalent examples for the NESTOR and MEUST cables are shown in Figures S2 and S3,

(a)

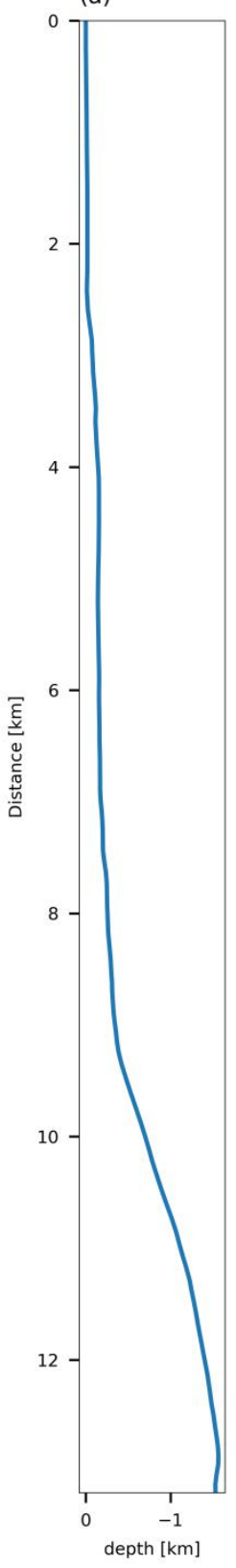

(b)

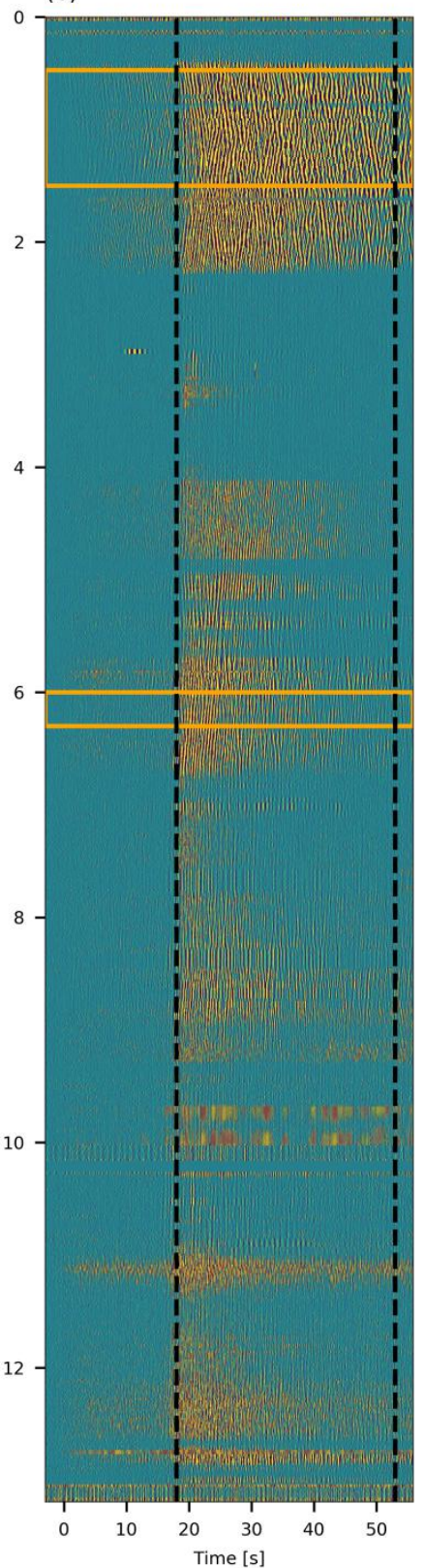

(c)

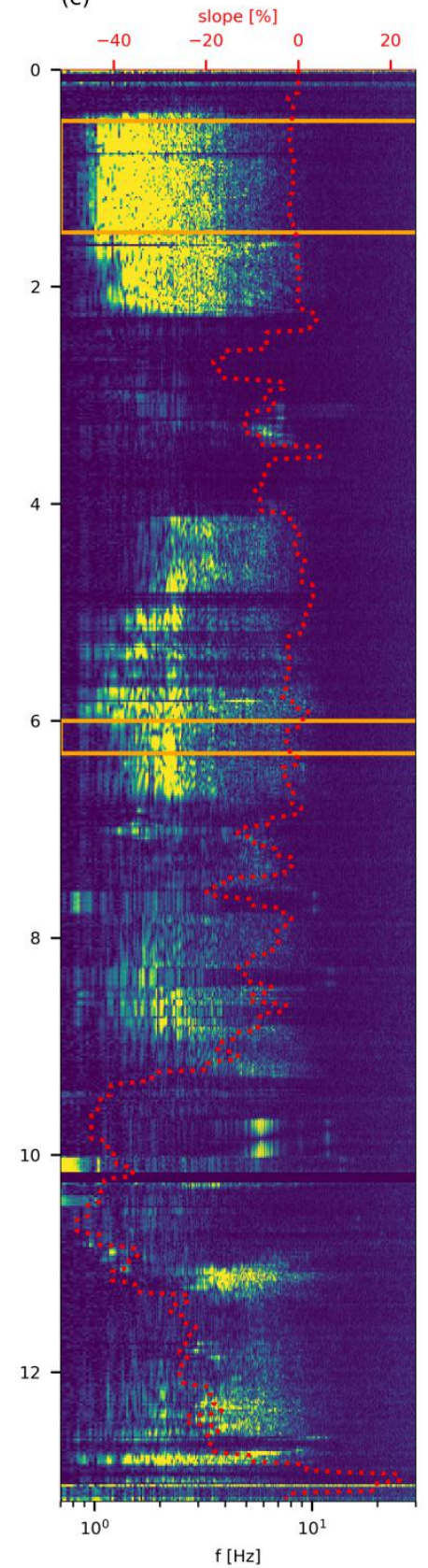

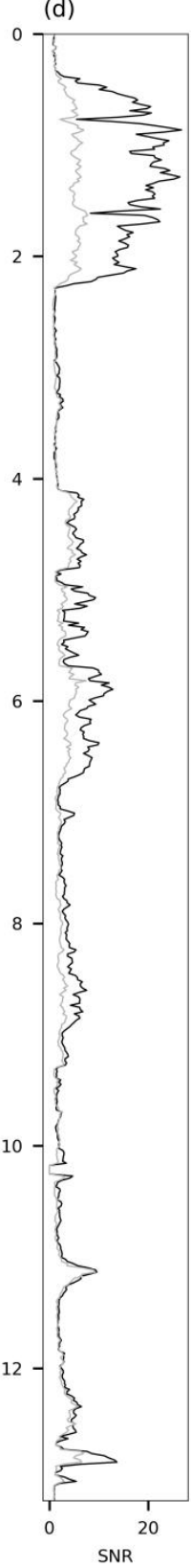

Figure 4: Example of a M3.7 earthquake at approximately $125 \mathrm{~km}$ recorded by HCMR. a) depth profile, b) earthquake signals, c) spectra and d) signal to noise ratios along the cable's path. Time in panel $b$ is relative to the theoretical $P$-wave arrival at the cable position of $0 \mathrm{~km}$ (closest point to the earthquake epicenter). Swave spectra in (c) are computed in the interval indicated by dashed black lines in (b). The slope of the cable is plotted in red in panel c. Sections that are used in subsequent analysis are indicted by orange rectangles. 
respectively). The cable's depth profile (panel a), earthquake time series (panels b), spectra (panels c) and signal-to-noise-ratio (SNR) (Panels d) are plotted as a function of distance along the fiber. These signals are extremely segmented and exhibit amplitude and frequency shifts and jumps (e.g., 5 to $6 \mathrm{~km}$ ). While several cable segments record high amplitude seismic signals, others exhibit very weak amplitudes (e.g., 2.5 to $4 \mathrm{~km}$ ), or lack seismic signals as seen by the onshore cable segment ( 0 to 400 meters). SNR were calculated in the frequency-domain by considering signal and noise (obtained in section 3) amplitudes between 1 and $15 \mathrm{~Hz}$. In panel d, SNR are plotted for the displayed earthquake (black curve) and the other analyzed event on the HCMR cable (gray curve). The similarity between SNR patterns along the fiber for different earthquakes (also seen in Figures S2 and S3) indicates that this cable specific property may be used to quantify groundcable coupling as well as ground deformation amplifications along the cable.

Sections where signals are weak typically correspond to irregular bathymetry, while high amplitude seismic deformations are measured by fiber segments deployed on flat or smooth bathymetry. The latter may be due to the presence of sediments which control amplification and slowness, while the former, may suggest uneven coupling and/or lack of sediments. This correlation is evident when comparing the recorded signals' quality with the bathymetry (Figure 4a) and slope (red dotted curve in Figure 4c) along the cable. For example, shallow sections of HCMR and NESTOR record highenergy signals (Figures 4 and S2): these segments are deployed inside Methoni bay, a sedimentary basin characterized by flat bathymetry and low velocities (section 4.2). The smooth SNR increase and decrease when entering and exiting the bay (Figures $4 \mathrm{~d}$ and $S 2 \mathrm{~d}$ ) suggests the presence of a sedimentary basin: as sediment thickness increases from the edges towards the middle of the basin, so does ground motion amplification. This SNR pattern is thus indicative of cable segments traversing sedimentary basins.

In-spite of the often unfavorable ocean-bottom - cable coupling, several cable segments record sufficiently uniform signals for seismic analysis and specifically, apparent velocity estimation. Two such sections are identified for each cable, indicated by orange lines in panels $b$ and $c$ of Figures 4, S2 and S3. Their signals are analyzed in the following sections.

\subsection{Strain-rate to ground motions conversion}

To further investigate the response of underwater DAS to transient ground deformations, DAS signals are compared to the ground motion measurements recorded by nearby seismometers. To convert strain-rate records to ground motions, phase velocities need to be determined. Here, we use the waves' apparent phase velocities along the fiber, assuming the signal is dominated by a single plane wave:

$$
\dot{\epsilon}_{x \chi}=\frac{\partial U_{\chi}}{\partial t \partial x}=\frac{\partial V_{\chi}}{\partial x}=\frac{\partial V_{\chi}}{\partial t} \frac{\partial t}{\partial x}=A_{x} \frac{1}{C_{\chi}},
$$


where $\dot{\epsilon}_{x x}, U_{x}, V_{x}, A_{x}$ and $C_{x}$ are the strain-rate, ground displacements, ground velocities, ground accelerations, and apparent phase velocity along the fiber ( $x$ direction), respectively. The relation between the phase velocity $C$ and the apparent phase velocity is: $C_{x}=C / \cos \theta$, where $\theta$ is the angle between the wave's propagation direction and the fiber. The apparent velocity is expected to change along the cable due to local conditions, sedimentary cover, seismic wave velocities and propagation direction with respect to the cable's orientation. Here, apparent velocities are estimated via frequency-wavenumber ( $f-k)$ analysis, and DAS strain-rate measurements are converted to ground accelerations in the frequency-domain. DAS converted spectra are then compared to broadband seismometer spectra.

Apparent velocities are reliably estimated using homogeneous DAS signals recorded on sufficiently long cable segments. Phase apparent velocities are defined as $f / \nu$ where $f$ and $\nu$ are the temporal and spatial frequencies, respectively. This analysis is performed on the segments identified in the previous section (orange lines in panels $b$ and $c$ of Figure 4, S2 and S3). Example f-k plots are shown in Figure 5 (top panels) for four earthquakes recorded on the NESTOR cable between 0.35 and $1.5 \mathrm{~km}$ from the interrogator, on a section deployed in Methoni bay. Similar f-k plots for all cable segments are shown in Figures S4-S8.

The observed low apparent velocities, generally symmetric f-k plots,

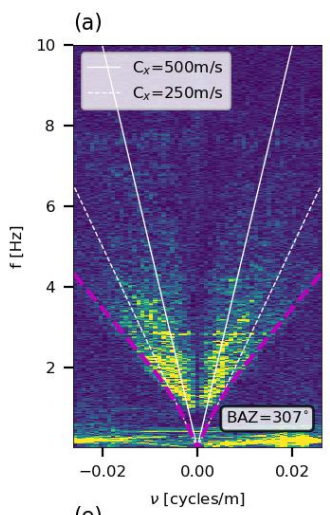

(b)

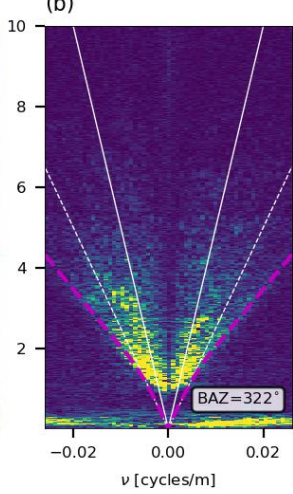

(c)

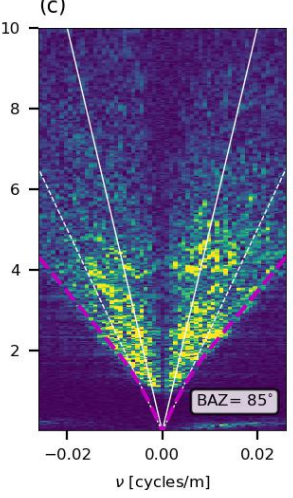

(d)

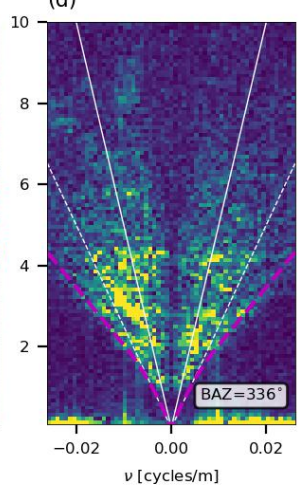

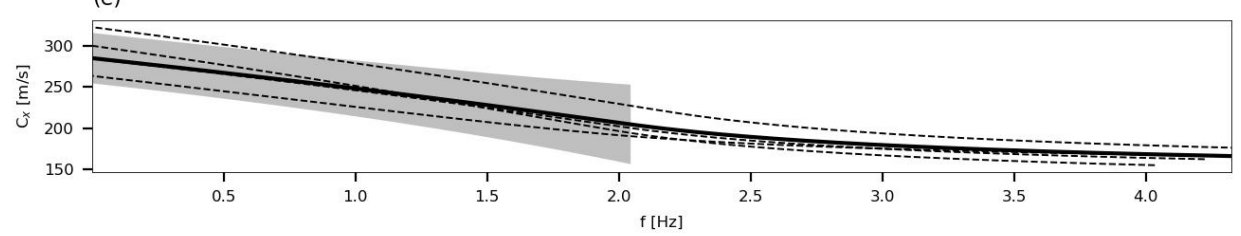

Figure 5: Panels a-d: Examples of $\mathrm{f}-\mathrm{k}$ plot for four earthquakes on a segment of the NESTOR cable from 0.35 to $1.5 \mathrm{~km}$. The empirical dispersion curve is indicated in magenta in panels a-d and in panel e. White lines correspond to non-dispersive phase velocities of $500 \mathrm{~m} / \mathrm{s}$ (solid line) and $250 \mathrm{~m} / \mathrm{s}$ (dotted line). Panel (e) shows the apparent velocity as a function of frequency obtained for all earthquakes at once (solid black curve) and for each event individually (dashed black curves). Shaded gray area indicates one standard deviation to solid black curve's fit. The dispersion for $\mathrm{f}>2 \mathrm{~Hz}$ was linearly extrapolated from the fitted curve. 
and similarity between different earthquakes with different back-azimuths (receiver-to-source azimuth), suggest that underwater DAS signals are dominated by Scholte-waves propagating in a broad range of horizontal directions. These dispersive waves are a result of body-wave scattering, and their polarization is radial and vertical, similar to that of Rayleigh waves. Since the analyzed fiber segments are installed on typically flat bathymetry, the radial polarization dominates DAS measurements. Strain-rate measurements of waves propagating at an angle $\theta$ relative to the fiber's axis are modulated by a $\cos ^{2} \theta$ (e.g., Kuvshinov et al., 2016; Mateeva et al., 2014), significantly reducing the amplitude of waves closer to normal incidence. Thus, it is expected that the highest amplitude waves recorded by DAS are those traveling along the fiber, with $C_{x}=C$ (note that generally $C_{x} \leq C$ ), i.e., the lowest apparent velocity in the $\mathrm{f}-\mathrm{k}$ plot (top panels of Figure 5). Thus, the phase velocity used for DAS to ground motion conversion is the lowest appartent velocity, represented by the purple curve in Figure 5 which separates the low and high energy regions in the f-k plots. Apparent velocities as a function of frequency, deduced from the curves in Figure 5, are shown in panel e. The dispersive nature of the waves further supports the conclusion that these are Scholte-waves.

Apparent velocities (purple curve in Figure 5) are obtained for all analyzed events per cable segment. That $\mathrm{f}-\mathrm{k}$ plots are symmetric and similar for different earthquakes recorded by the same segment suggests similar propagation characteristics, as expected for scattered waves: their propagation and velocity is dictated by local heterogeneities and velocity model. Thus, the same apparent velocity is used for all analyzed earthquakes regardless of source and backazimuth variations. For each event in a specific cable segment, the boundary between the low and high energy regions (top panels of Figure 5) is determined per frequency by a simple amplitude threshold condition. Then, these $f-\nu$ combinations are averaged per spatial-frequency $\nu$ for all available events, and fitted with a third degree polynomial passing through $f=\nu=0$. From a certain frequency, this polynomial is linearly extrapolated to obtain the purple curve in Figure 5. Apparent velocity errors are represented by the gray region in Figure $5 \mathrm{e}$, indicating one standard deviation for frequencies corresponding to the polynomial fit ( $f<2 \mathrm{~Hz}$ in Figure 5 ). For comparison, dispersion curves were obtained independently for each earthquake following the same procedure (dashed curves in Figure 5e). The standard deviation of the different event specific curves are small: 18.9 and $8.6 \mathrm{~m} / \mathrm{s}$ at 1 and $4 \mathrm{~Hz}$, respectively, further justifying the use of a single dispersion curve for all earthquakes. For several cable segments, the spatial resolution is inadequate (short cable segments on HCMR and NESTOR, Figures S4 and S5) and f-k plots were fitted with a simpler linear equation passing $f=\nu=0$, corresponding to nondispersive waves. In the following section, broadband sensors' acceleration records are converted to strain-rate using the empirical apparent velocities 
obtained per cable segment. Converted broadband spectra are then compared to DAS spectra.

\subsection{DAS and broadband comparison}

Broadband earthquake acceleration spectra are converted to strainrate and compared with DAS measurements. The conversion was done using the same dispersion curve (Figure 6) or single apparent velocity (Figure 7) for each cable segment. Here, broadband spectra were corrected for hypocentral distance to match with the different DAS fiber segments. Figures 6 and 7 show DAS strain-rate time series along the cable (left panels), Swave spectra along the cable (middle panels), and a comparison between DAS and broadband converted strain-rate spectra (right panels) for 4 earthquakes recorded on the NESTOR cable. In the right panels, DAS earthquake spectra and mean noise (obtained in section 3) for each measurement point along the cable segment are plotted as thin black and red curves, respectively, while stacked signal and noise are plotted as thick black and red curves, respectively. These earthquake spectra are resampled in the same manner as noise spectra (McNamara and Buland, 2004) for comparability.

Broadband converted acceleration spectra agree with DAS strain-rate spectra when the latter are corrected for site effects. Excellent agreement is observed between DAS and broadband converted spectra for the two closest events in Figure 6 (M2 at $49 \mathrm{~km}$ and a depth of $2 \mathrm{~km}$, and M2.6 at $63 \mathrm{~km}$ and a depth of $9 \mathrm{~km}$ ), while the agreement for farther earthquakes is less favorable (M3.3 at $130 \mathrm{~km}$ and a depth of $11 \mathrm{~km}$, and M3.6 at $149 \mathrm{~km}$ and a depth of $7 \mathrm{~km}$ ), possibly a result of different propagation effects. In contrast, DAS spectra in Figure 7, recorded in Methoni bay, are rich in low frequencies and poor in high frequencies. Similar behavior is observed for HCMR, when comparing signals recorded outside (Figures S5) and inside (Figures S6) Methoni bay, as well as for different MEUST sections (Figures S7 and S8). The amplification observed for MEUST (Figure S8) is related to the secondary microseismic peak (Figure 2), while that observed in Methoni bay is related to the presence of a low velocity (Figure 5 and S6) basin, as suggested by the noise peak at 1-2 $\mathrm{Hz}$ (Figure 2). The stronger attenuation inside the basin may be modeled by a decaying exponential term in the form: $\exp (-\Pi \Delta K f)$ (Anderson and Hough, 1984), where $\Delta K$ indicates additional attenuation. Imposing such attenuation on the observed broadband spectra (dashed curves in the right panels of Figure 7) results in good agreement between high frequency DAS and broadband spectra.

To quantify the amplification and attenuation observed by HCMR and NESTOR, the ratio between DAS spectra recorded inside and outside Methoni bay is inspected in Figure 8. The seemingly tapered edges of these curves represent the signals' amplitudes falling below background noise levels, thus, 
only frequencies between $\sim 1$ and $\sim 15 \mathrm{~Hz}$ (depending on SNR) should be considered. Earthquakes recorded inside Methoni bay show significant amplification of up to a factor of 10 at frequencies of 1 to $2 \mathrm{~Hz}$, and stronger attenuation in the 2 to $20 \mathrm{~Hz}$ band compared with signals recorded outside the bay. This behavior is indicative of sedimentary basins, which are
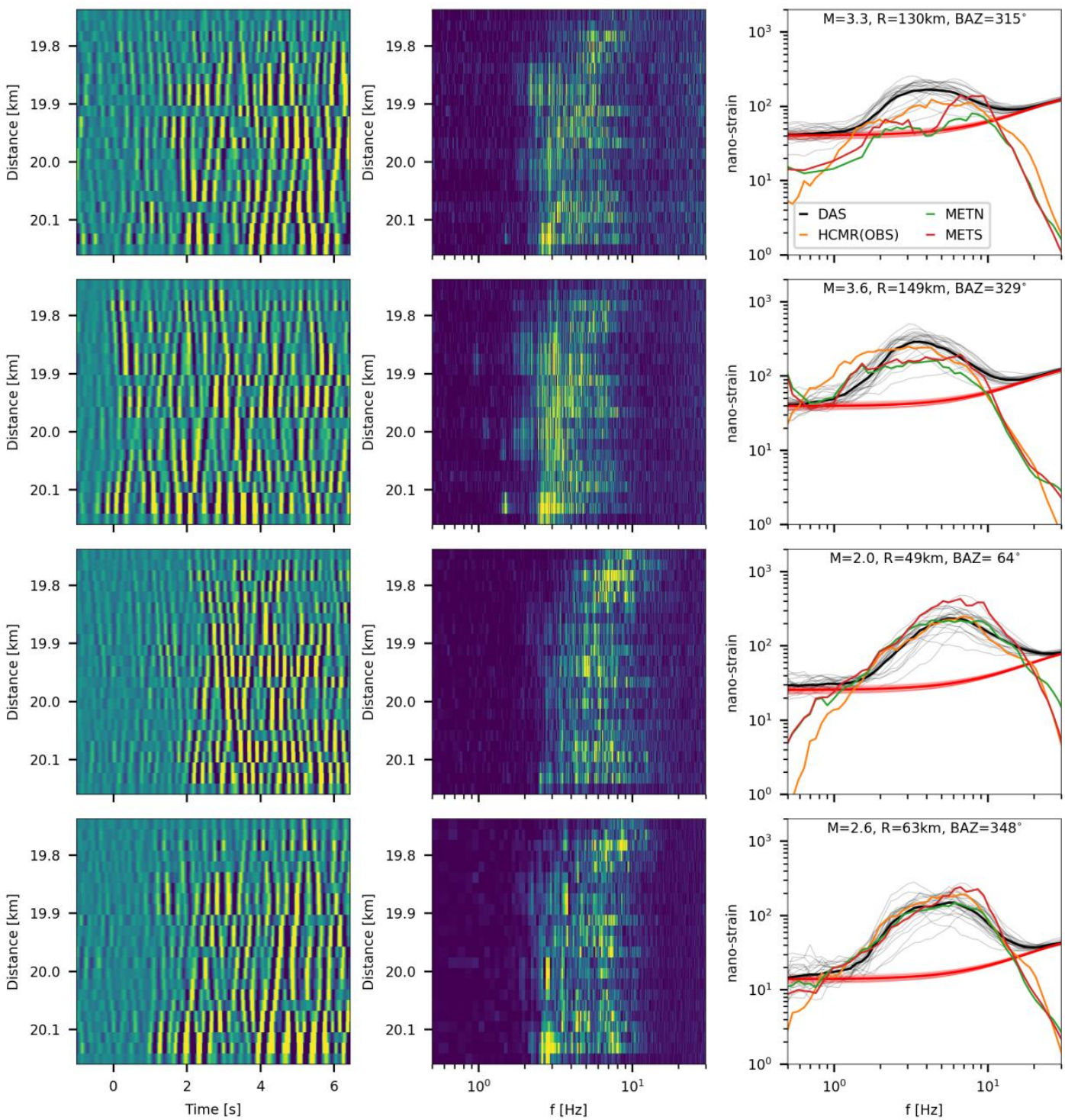

Figure 6: Spectral analysis for 4 earthquakes recorded by NESTOR between 19.7 and $20.2 \mathrm{~km}$ from the interrogator, between 3.1 and $3.3 \mathrm{~km}$ depth. Left panels: time series, middle panels: spectra, right panels: strain spectra and converted broadband spectra. Plotted time series (left) were filtered between 1 and $5 \mathrm{~Hz}$. Time in the left panels is relative to the start of the analyzed interval. In the right panels, DAS earthquake and noise spectra for each measurement location along the fiber are indicated by thin black and red curves, respectively, while averages are indicated by thick lines. Green and dark red curves correspond to records from on-land seismometers near the on-land end of the fiber, while the orange curve corresponds to the record of an OBS installed at the end of the HCMR cable. 
442 generally characterized by low seismic velocities (e.g., Courboulex et al., 443 2020; Pratt et al., 2003).

$444 \quad$ In the next section, we quantify the ability to detect seismic signals 445 using underwater DAS and compare it to that of broadband seismometers.

446

447

448

449

450

\section{Implications for DAS Detection Capabilities}

The results presented in the previous section, in particular the conversion between strain and ground motions, based on apparent velocities estimated on each cable segment, are used here to analyze underwater DAS single-channel signal-to-noise ratio (SNR) capabilities, and compare them to
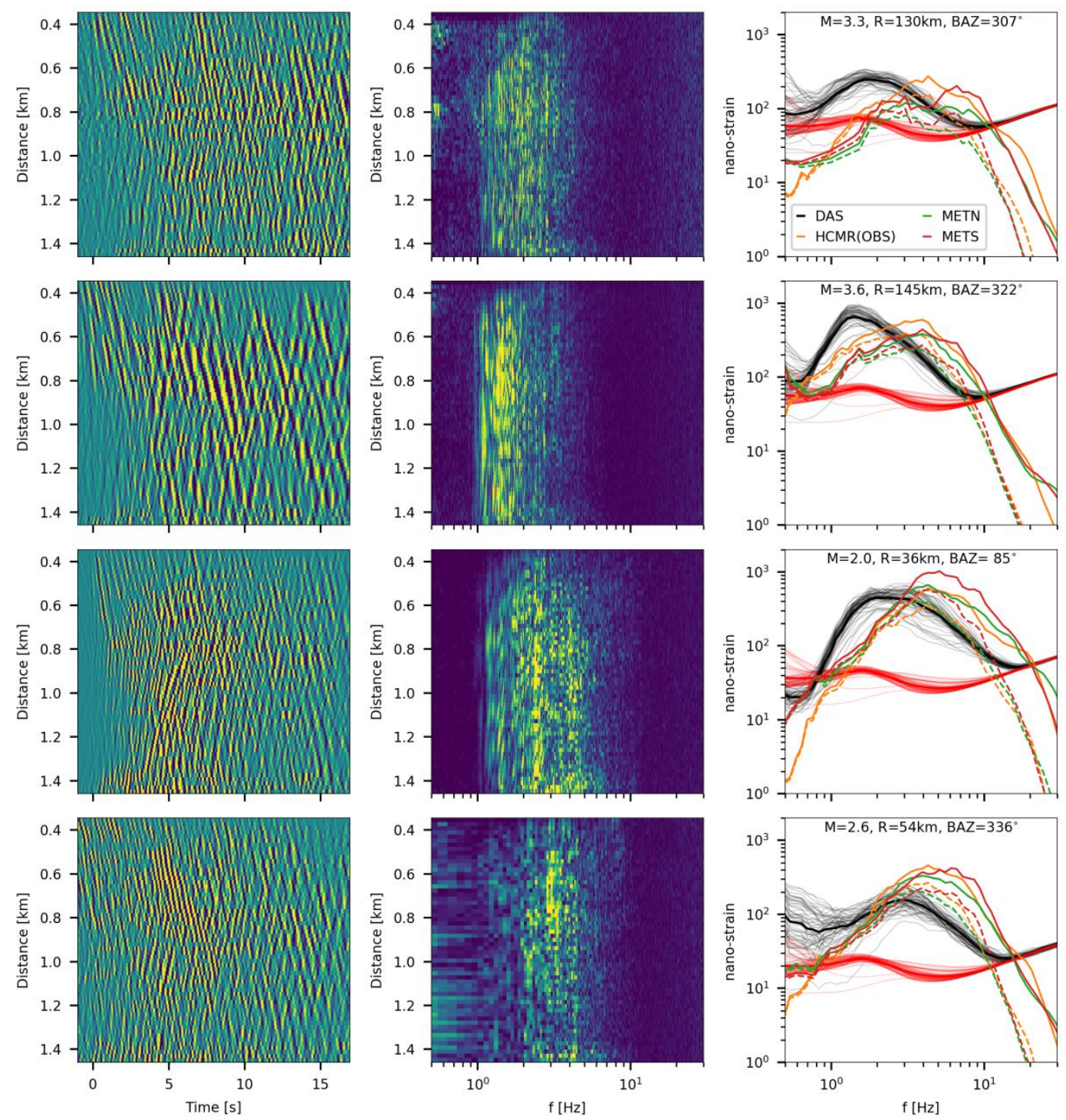

Figure 7: As in figure 6 for a section between 0.35 and $1.5 \mathrm{~km}$ from the interrogator, between 3 and $18 \mathrm{~m}$ depth. Dashed curves indicate strain-rate converted broadband spectra subject to additional attenuation ( $\triangle \mathrm{kappa}=0.04$ seconds). 


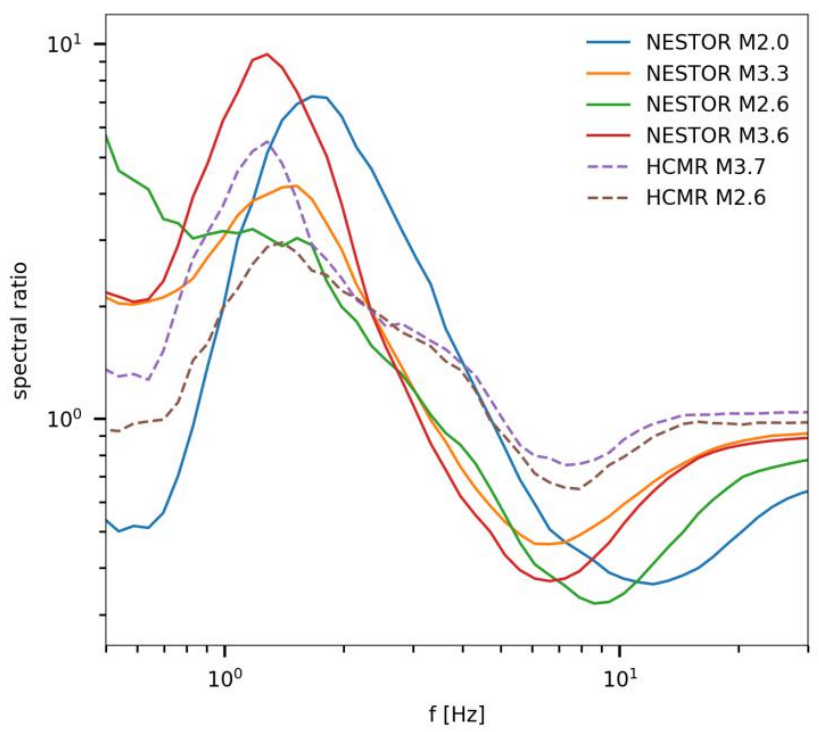

Figure 8: Methoni bay amplification. Spectral ratios of distance corrected DAS spectra for events recorded in and out of Methoni bay: thick black curves in right panels of figure 7 (NESTOR) and S5 (HCMR) divided by thick black curves in right panels of figure 6 (NESTOR) and S4 (HCMR), respectively.

\section{those of broadband seismometers. For a valid comparison, this analysis} treats DAS signals as independent channels. The spatial coherency between waveforms recorded along the optical fiber, a unique strength of DAS facilitating the implementation of high-performance array detection methods (e.g., Lindsey et al., 2017; Rost and Thomas, 2002), is expected to enhance earthquake detection capabilities, but is not exploited here. In that sense, our analysis is a conservative estimate of the performance of seafloor DAS relative to conventional seismometers. In this section, only the new generation interrogator is considered, since it better represents state-of-theart DAS capabilities. Because the earthquakes we have recorded are typically observed at $f>1 \mathrm{~Hz}$ (Figures 5, 6 and 7), this analysis is limited to this frequency band.

\subsection{S-wave detection on horizontal underwater fibers}

DAS detection capabilities are analyzed by considering an earthquake model, DAS noise (obtained in section 3 ), and the apparent velocities (obtained in section 4.2). Earthquake acceleration spectra are simulated using the omega-squared model (Brune, 1970; Madariaga, 1976) describing far field body-wave radiation, and subject to high frequency attenuation (Anderson and Hough, 1984). This model is found to be in good agreement with observed DAS and broadband spectra (not shown). The model, and associated parameter tuning, are described in the supplementary. Horizontally deployed fibers exhibit higher sensitivity to S-waves than Pwaves, a function of the phase's polarization with respect to the fiber (e.g., Kuvshinov, 2016; Mateeva et al., 2014; Papp et al., 2017). Owing to the lower velocities and higher amplitudes of S-waves, they display higher strain 
amplitudes, compared with P-waves (section 6). Thus, only S-waves are considered in the following analysis. To determine DAS detection thresholds, i.e., signal to noise ratios in a certain frequency-band, for specific cable segments, DAS strain-rate are converted to acceleration noise PSDs (Equation 1) and compared to the earthquake model.

Using the apparent velocities for the slow Scholte-waves (e.g., Figure 5), detection thresholds are found to be similar for DAS and broadband seismometers. Figure 9 shows detection thresholds for MEUST at 12.4 and $30.2 \mathrm{~km}$ from the interrogator, along with those of adjacent on-land (POSAS) and ocean-bottom (ASEAF) broadband seismometers. Detection thresholds are compared to ground motion accelerations for earthquakes of magnitudes 1 and 2 at a hypocentral distance of $50 \mathrm{~km}$. These thresholds indicate great similarity between the detection capabilities of DAS (solid curves in Figure 9) and nearby broadband OBS (dotted orange curve in Figure 9) for the same underwater environment and noise conditions (section 3 ).

The ability to detect a seismic signal using DAS greatly depends on the apparent velocity: at similar acceleration amplitudes, the slower the wave, the higher its strain-rate values (Equation 1). This is illustrated in Figures 10 and 11 , by modeling DAS and broadband SNR values for different magnitude earthquakes between 1 and $15 \mathrm{~Hz}$. Signals are simulated using the same earthquake model used in Figure 9 at a hypocentral distance of $50 \mathrm{~km}$

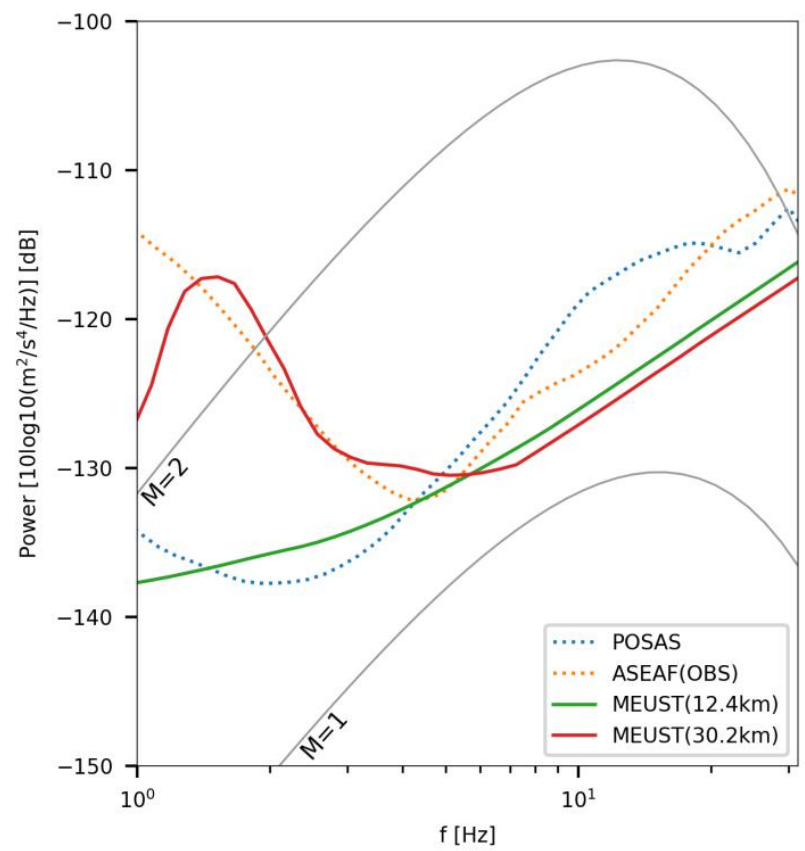

Figure 9: DAS and broadband noise spectra compared to theoretical S-wave spectra. Magnitudes 1 and 2 at distances of $50 \mathrm{~km}$ and $\mathrm{K}=0.04$ seconds are indicated by solid gray curves. Representative DAS noise curves are shown for MEUST at $12.4 \mathrm{~km}$ (solid green) and $30.2 \mathrm{~km}$ (solid red). Noise curves for broadband seismic stations on-land POSAS and underwater ASEAF, located near MEUST, are indicated by dotted blue and orange curves, respectively. 


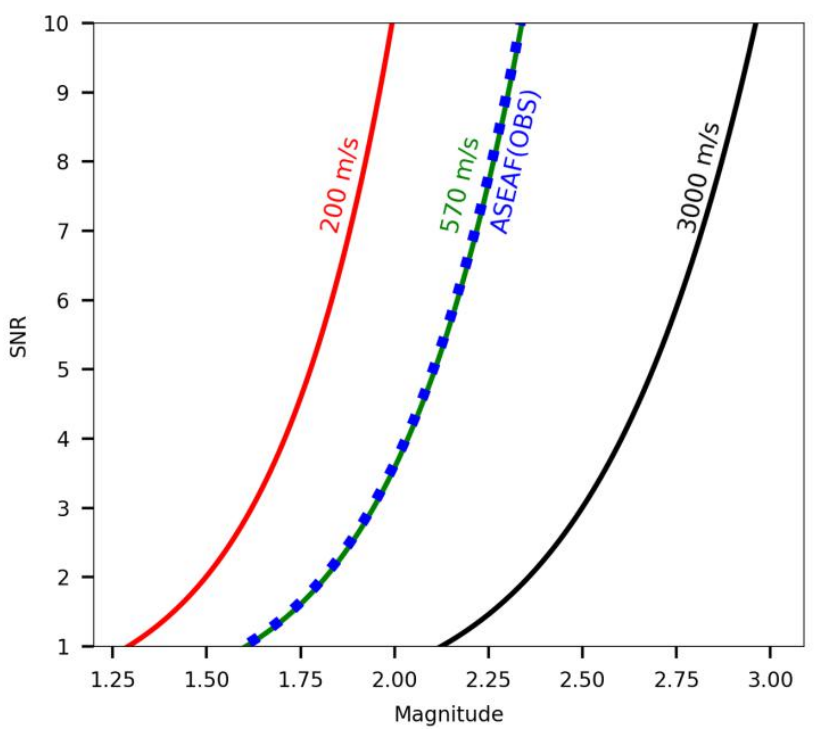

Figure 10: S-wave SNR calculated between 1 and $15 \mathrm{~Hz}$ for ground accelerations as a function of magnitude. Earthquake spectra were simulated at a hypocentral distance of $50 \mathrm{~km}$ and $\mathrm{k}=0.04$ seconds. DAS noise, calculated on MEUST at 12.4 $\mathrm{km}$ from the interrogator, was converted to ground accelerations using several nondispersive apparent velocities. SNR for ASEAF (the OBS at the end of MEUST) are indicated by the dotted blue curve. SNR for DAS with apparent velocities of 200, 570 and 3000 m/s are indicated by solid red, green and black curves, respectively.

(Figure 10) and for various distances (Figure 11). Acceleration spectra noise thresholds are obtained for MEUST at $12.4 \mathrm{~km}$ from the interrogator using different non-dispersive apparent velocities. The apparent velocity is used to convert DAS strain-rate to acceleration detection threshold, while modeled earthquake acceleration spectra do not account for apparent velocities (supplementary materials). This analysis indicates that for a specific phase velocity, DAS and broadband SNR are equivalent (green and blue curves in Figure 10), while slower and faster waves produce higher and lower SNR on DAS, respectively. In Figure 11, SNR $=1$ curves are plotted for different magnitude-distance combinations, constituting detection thresholds for various apparent velocities: waves to the right of each curve are detected while those to the left are not. This plot may be used to evaluate the ability to reliably use S-waves for seismic monitoring for different magnitudes and distances.

The presented analysis indicates that for a given earthquake, and depending on the ground motion amplitudes, slow phases (e.g., scattered and surface waves) may be detected, while fast phases (e.g., body waves) may not. For instance, plotting DAS earthquake (black) and noise (red) spectra at two different HCMR cable segments (Figure 12), we can observe either low velocity $(240 \mathrm{~m} / \mathrm{s})$ high energy strain-rate signals (from $\mathrm{km} 6$ to 6.3 , Figure S5), or high velocity $(1690 \mathrm{~m} / \mathrm{s})$ low energy strain-rate signals (from $\mathrm{km} 2.3$ to 2.85, Figure S9). Both slow and fast waves are detected for the M3.7 earthquake (panel a), while only slow waves are detected for the 


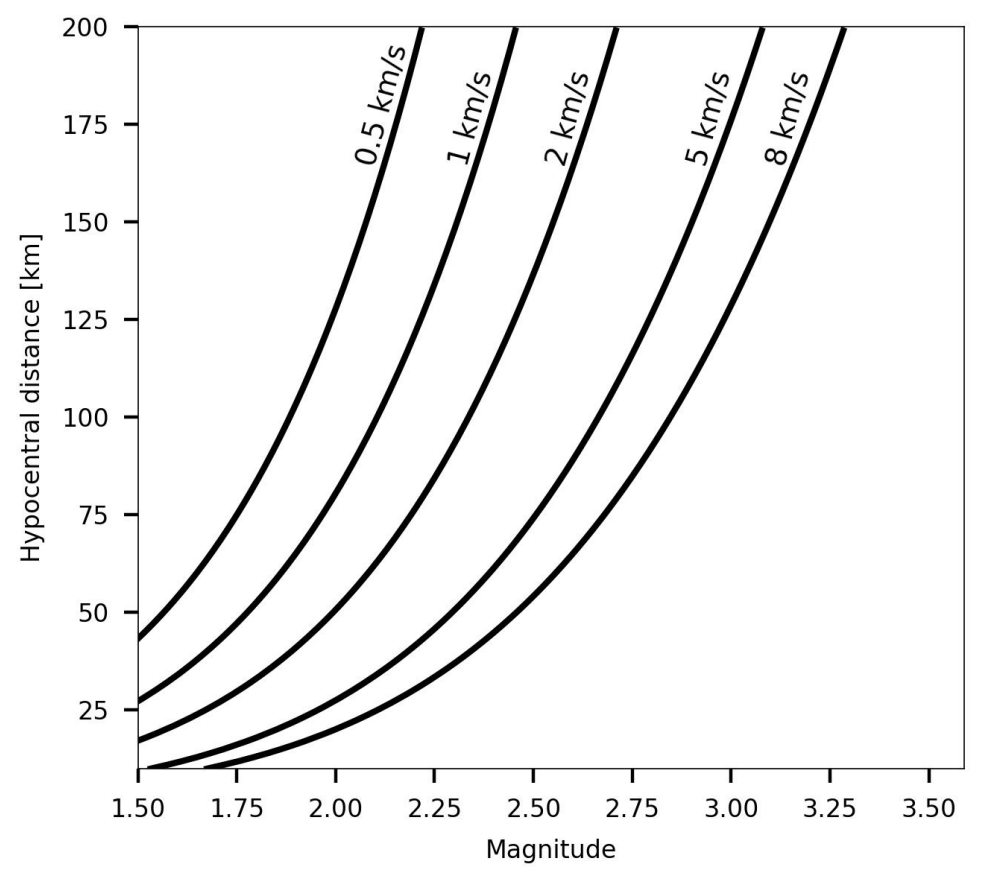

Figure 11: S-wave detection thresholds $(\mathrm{SNR}=1)$, calculated between 1 and $15 \mathrm{~Hz}$, for ground accelerations at different apparent velocities. Earthquake spectra and noise were simulated as in Figure 10 for various magnitudes and hypocentral distances. For each apparent velocity, S-waves at magnitudes-distances to the right of each curve are above noise level.

M2.6 earthquake (panel b). Broadband converted strain-rate spectra of the HCMR OBS using the obtained apparent velocities (orange curves) further show that the fast waves of the M2.6 earthquake are below DAS noise levels (dashed orange curve in panel b). Since both analyzed earthquakes display similar backazimuths and distances, and thus similar propagation characteristics, the apparent velocity obtained for the M3.7 earthquake (Figure S9) is used to convert the broadband spectra of the M2.6 earthquake to strain-rate (orange dashed curve in Figure 12b).

In this analysis, on-land cable segments did not measure any earthquake ground deformations. The longest on-land section is that of MEUST, deployed for $1.6 \mathrm{~km}$ : from the interrogator's position to the coast, along a two-lane motorway. This segment displays noise levels similar to those recorded at deeper underwater segments (Figure 3c), and clearly records vehicles driving along the road. That no seismic signals are recorded on this segment is interpreted as a result of high apparent velocities, in agreement with previous studies, which show that on-land Rayleigh waves are faster than ocean-bottom Scholte-waves (e.g., Kruiver et al., 2010; Park et al., 2005). This observation suggests that DAS detection capabilities are enhanced for underwater fibers compared with those installed on-land. Since unlike DAS records, ground motion amplitudes (and thus broadband detection capabilities) are invariant to the wave's velocity, OBS are not expected to outperform on-land seismometers. 
(a)

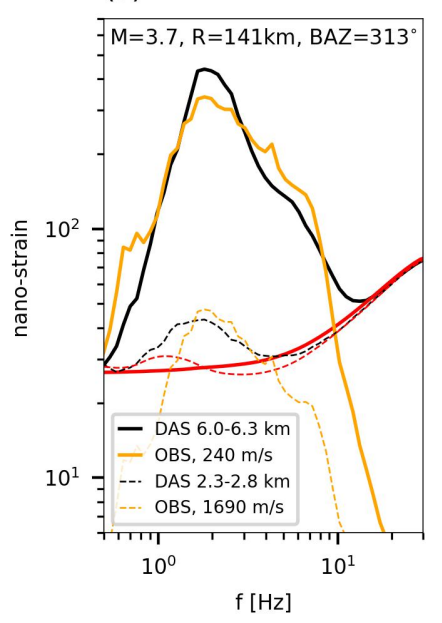

(b)

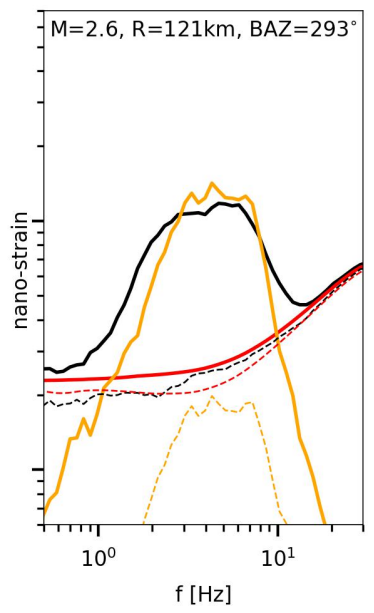

Figure 12: Comparison between earthquakes recorded by two cable segments on HCMR. Thick solid curves and thin dashed curves correspond to stacked DAS spectra (black), stacked DAS noise (red) and broadband converted strain-rate. Broadband spectra was converted to strain-rate using different apparent velocities as noted by the legend. Magnitudes, distances and BAZ values are indicated in the top of each panel.

5.2 P-wave detection on horizontal underwater fibers and implications for earthquake early warning

That fast waves may not be detected by DAS has significant implications for several seismological tasks that rely on the information carried by fast direct body-waves. These objectives include the determination of earthquake location and source parameters, both crucial for seismic monitoring and, in particular, for EEW. Using the P-waves is particularly advantageous for EEW since waiting for the S-waves comes at the cost of delaying alert issuance. However, the detection capabilities of fast, low amplitude, P-waves on horizontal optical fibers is hindered by both the high apparent velocities and near-vertical incident angles; vertically incident P-waves induce transverse deformations on a horizontal cable, while fibers are mostly sensitive to longitudinal deformations. The response of a fiber optic cable to waves propagating at an angle $\theta$ with respect to the fiber is modulated by $\cos ^{2} \theta$. Though signals do not vanish completely at $\theta=90^{\circ}$ (Kuvshinov et al., 2016; Mateeva et al., 2014, Papp et al., 2017), they have much smaller amplitude and will hardly be detected.

In practice, P-waves are detected since underwater cables follow the bathymetry and are thus not strictly horizontal (panels c-e of Figure 1), and since incidence angles, especially for scattered P-waves, would typically be smaller than $90^{\circ}$. Even for small magnitudes at large distances, as those analyzed, scattered P-waves are observed for several earthquakes (e.g., in Methoni bay, Figure 4). Thus, for earthquakes relevant for EEW, i.e., medium to big magnitudes at close distances, whose ground motion accelerations are expected to be $\sim 2$ orders of magnitude higher than those recorded here 
(e.g., Lior and Ziv, 2020) (Figures 6 and 7). This indicates that underwater telecommunication cables may be reliably used for P-wave detection and thus for EEW, improving alert times for underwater earthquakes. In-depth quantitative analysis of this issue requires further research, beyond the scope of this manuscript, and additional high amplitude earthquake observations.

If P-waves cannot be reliably analyzed, the use of S-waves for both tasks is still expected to yield robust estimates, at the cost of time delays. For closely recorded earthquakes, relevant for EEW, these delays are expected to be small, since S-waves follow P-waves by approximately R/8 seconds, where R is the hypocentral distance in $\mathrm{km}$ (e.g., Lior and Ziv, 2018).

\section{Conclusions}

This study presents the most comprehensive analysis to-date of underwater DAS measurements, addressing both noise and earthquake recordings along three underwater dark fibers in the Mediterranean Sea. This analysis presents various noise sources including surface gravity waves, secondary microseisms and local basin resonance. The effect of these noise sources, as well as ocean-bottom - cable coupling, on measured ground deformations is demonstrated using several small $(M w<3.7)$ well recorded regional earthquakes. Finally, the ability to detect seismic phases using underwater DAS is discusses for both P- and S-waves.

A significant correlation is observed between irregular bathymetry and unfavorable DAS measurements (Figures 4, S2 and S3). Flat or smooth bathymetric slopes typically correspond to sediment accumulating regions, while irregular bathymetry prevents sediment deposition. Sedimentary basins are characterized by low seismic velocities (e.g., Figure 5) and excellent coupling (e.g., Figure 4), while regions that lack sedimentary cover are characterized by higher seismic velocities. In addition, deploying underwater fibers over irregular bathymetry may result in uneven coupling and even cable segments hanging in the water column. It is concluded that the bathymetry dictates the measurement quality, by modulating phase velocities and ground-cable coupling.

Frequency-wavenumber analysis indicates that underwater DAS earthquake records are dominated by slow scattered dispersive Scholtewaves. Broadband earthquake spectra are converted to strain-rate using apparent velocities obtained via $\mathrm{f}-\mathrm{k}$ analysis. Since this analysis was done for scattered Scholte-waves, a single apparent velocity or dispersion curve was used for all earthquakes recorded by the same cable segment. However, when analyzing direct phases, apparent velocities will differ depending on the propagation path and wave-fiber incidence angle, requiring an earthquake specific analysis. Excellent agreement is found between DAS and converted broadband spectra, when the latter is corrected for local amplification and attenuation effects. A local sedimentary basin is identified 
using both coherent noise and earthquake signals, and is shown to amplify and attenuate low and high frequency seismic signals, respectively.

Detection capability analysis indicates the great potential of underwater DAS for earthquake detection and monitoring. DAS detection capabilities are found to be strongly correlated with apparent velocities: for the same ground motion amplitudes, slow and fast waves induce high and low energy DAS strain records, respectively. DAS and broadband detection abilities were found to be similar for the recorded earthquake phases (Figure 9). That on-land sections did not record the analyzed earthquakes is attributed to higher on-land velocities, a phenomenon that suggests that DAS detection capabilities are enhanced underwater. Our conservative analysis does not use the spatial coherence of DAS data, a powerful property that may be used to denoise coherent signals. Thus, the ability to analyze earthquakes using underwater DAS is expected to be superior to that of broadband sensors, even for equivalent SNR.

The results demonstrate the great potential of underwater DAS for seismic monitoring and for providing EEW using standard underwater telecommunication cables. The latter will greatly enhance hazard mitigation capabilities, increase warning times for underwater earthquakes, and potentially save many lives.

\section{Acknowledgments and Data}

DAS data were acquired using a first generation Febus Al interrogator and an Aragon Photonics hDAS interrogator. Broadband seismometer data were acquired by Géoazur except for OBS records: data for the ASEAF station were downloaded from RESIF (http://seismology.resif.frl, last accessed May 2020). The MEUST infrastructure is financed with the support of the CNRS/IN2P3, the Region Sud, France (CPER the State (DRRT), and the Europe (FEDER). This work and IL were supported by the SEAFOOD project, funded in part by grant ANR-17-CE04-0007 of the French Agence Nationale de la Recherche. Part of the project was also supported by Université Côte d'Azur IDEX program UCAJEDI ANR-15-IDEX-0001 and the Doeblin Federation (FR2800 CNRS). The fiber optic DAS earthquake recordings used to generate Figures 4, S2 and S3, and the curves plotted in Figure 3 are available in the following OSF repository: https://osf.io/4bjph/.

\section{References}

Allen, R. M., \& Melgar, D. (2019). Earthquake Early Warning: Advances, Scientific Challenges, and Societal Needs. Annual Review of Earth and Planetary Sciences, 471), 361-388. doi: 10.1146/annurev-earth-053018-060457

Aggouras, G., Anassontzis, E., Ball, A. E., Bourlis, G., Chinowsky, W., Fahrun, E., Grammatikakis, G., Green, C., Grieder, P., Katrivanos, P., Koske, P., Leisos, A., 
Ludvig, J., Markopoulos, E., Minkowsky, P., Nygren, D., Papageorgiou, K., Przybylski, G., Resvanis, L. K., \& Zhukov, V. A. (2005). Operation and performance of the NESTOR test detector. Nuclear Instruments and Methods in Physics Research Section A: Accelerators, Spectrometers, Detectors and Associated Equipment, 552, 420-439. doi: 10.1016/j.nima.2005.06.083

Anassontzis, E., \& Koske, P. (2003). Deep-sea station connected by cable to the shore. Sea Technology, 44, 10-14.

Anderson, J. G., \& Hough, S. E. (1984). A model for the shape of the fourier amplitude spectrum of acceleration at high frequencies. Bulletin of the Seismological Society of America, 74(5), 1969-1993.

Brune, J. N. (1970). Tectonic stress and the spectra of seismic shear waves from earthquakes. Journal of Geophysical Research, 75(26), 4997-5009. doi:

\section{$\underline{10.1029 / J B 075 i 026 p 04997}$}

Costa, L., Martins, H. F., Martin-Lopez, S., Fernandez-Ruiz, M. R., \& Gonzalez-Herraez, M. (2019). Fully Distributed Optical Fiber Strain Sensor With $10^{-12} \in / \sqrt{ } \mathrm{Hz}$ Sensitivity. Journal of Lightwave Technology, 3718), 4487-4495. doi:

\subsection{9/JLT.2019.2904560}

Courboulex, F., Mercerat, E. D., Deschamps, A., Migeon, S., Baques, M., Larroque, C., Rivet, D., \& Hello, Y. (2020). Strong Site Effect Revealed by a New Broadband Seismometer on the Continental Shelf Offshore Nice Airport (Southeastern France). Pure and Applied Geophysics. doi: 10.1007/s00024-019-02408-9

De Caro, M., Monna, S., Frugoni, F., Beranzoli, L., \& Favali, P. (2014). Seafloor Seismic Noise at Central Eastern Mediterranean Sites. Seismological Research Letters, 85(5), 1019-1033. doi: 10.1785/0220130203

Fernández-Ruiz, M. R., Soto, M. A., Williams, E. F., Martin-Lopez, S., Zhan, Z., GonzalezHerraez, M., \& Martins, H. F. (2020). Distributed acoustic sensing for seismic activity monitoring. APL Photonics, 5(3), 030901. doi: 10.1063/1.5139602

Finetti, I. (1982). Structure, stratigraphy and evolution of Central Mediterranean. Bollettino Di Geofisica Teorica Ed Applicata, 24 (96), 247-312.

Gabai, H., \& Eyal, A. (2016). On the sensitivity of distributed acoustic sensing. Optics Letters, 41(24), 5648. doi: 10.1364/OL.41.005648 
681

682

683

684

685

686

687

688

689

690

691

692

693

694

695

696

697

698

699

700

701

702

703

704

705

706

707

708

709

710

Kruiver, P. P., Deák, A., \& Allouche, N. E. (2010). Extraction of geotechnical properties from Scholte waves in underwater environments. cp-150-00013. doi: 10.3997/2214-4609-pdb.150.A05

Kuvshinov, B. N. (2016). Interaction of helically wound fibre-optic cables with plane seismic waves: Interaction of fibre-optic cables. Geophysical Prospecting, 64(3), 671-688. doi: $10.1111 / 1365-2478.12303$

Lamare, P. (2016). The MEUST deep sea infrastructure in the Toulon site. EPJ Web of Conferences, 116, 09001. doi: 10.1051/epjconf/201611609001

Lindsey, N. J., Dawe, T. C., \& Ajo-Franklin, J. B. (2019). Illuminating seafloor faults and ocean dynamics with dark fiber distributed acoustic sensing. Science, 366(6469), 1103-1107. doi: 10.1126/science.aay5881

Lindsey, N. J., Martin, E. R., Dreger, D. S., Freifeld, B., Cole, S., James, S. R., Biondi, B. L., \& Ajo-Franklin, J. B. (2017). Fiber-Optic Network Observations of Earthquake Wavefields: FIBER-OPTIC EARTHQUAKE OBSERVATIONS. Geophysical Research Letters, 44(23), 11,792-11,799. doi: 10.1002/2017GL075722

Lior, I., \& Ziv, A. (2018). The Relation Between Ground Motion, Earthquake Source Parameters, and Attenuation: Implications for Source Parameter Inversion and Ground Motion Prediction Equations. Journal of Geophysical Research: Solid Earth, 123(7), 5886-5901. doi: 10.1029/2018JB015504

Lior, I., \& Ziv, A. (2020). Generic Source Parameter Determination and Ground-Motion Prediction for Earthquake Early Warning. Bulletin of the Seismological Society of America, 11911), 345-356. doi: $10.1785 / 0120190140$

Longuet-Higgins, M. S. (1950). A Theory of the Origin of Microseisms. Philosophical Transactions of the Royal Society of London. Series A, Mathematical and Physical Sciences, 243(857), 1-35.

Madariaga, R. (1976). Dynamics of an expanding circular fault. Bulletin of the Seismological Society of America, 66(3), 639-666.

Martins, H. F., Martin-Lopez, S., Corredera, P., Salgado, P., Frazão, O., \& GonzálezHerráez, M. (2013). Modulation instability-induced fading in phase-sensitive optical time-domain reflectometry. Optics Letters, 38(6), 872. doi: 10.1364/OL.38.000872 
Mateeva, A., Lopez, J., Potters, H., Mestayer, J., Cox, B., Kiyashchenko, D., Wills, P., Grandi, S., Hornman, K., Kuvshinov, B., Berlang, W., Yang, Z., \& Detomo, R. (2014). Distributed acoustic sensing for reservoir monitoring with vertical seismic profiling: Distributed acoustic sensing (DAS) for reservoir monitoring with VSP. Geophysical Prospecting, 62(4), 679-692. doi: 10.1111/1365-2478.12116

McNamara, D. E., \& Buland, R. P. (2004). Ambient Noise Levels in the Continental United States. Bulletin of the Seismological Society of America, 94(4), 1517-1527. doi: $\underline{10.1785 / 012003001}$

Papp, B., Donno, D., Martin, J. E., \& Hartog, A. H. (2017). A study of the geophysical response of distributed fibre optic acoustic sensors through laboratory-scale experiments: Geophysical response of fibre optic sensors. Geophysical Prospecting, 65(5), 1186-1204. doi: 10.1111/1365-2478.12471

Park, C. B., Miller, R. D., Xia, J., Ivanov, J., Sonnichsen, G. V., Hunter, J. A., Good, R. L., Burns, R. A., \& Christian, H. (2005). Underwater MASW to evaluate stiffness of water-bottom sediments. The Leading Edge, 24(7), 724-728. doi: 10.1190/1.1993267

Peterson, J. R. (1993). Observations and modeling of seismic background noise (Report No. 93-322; Open-File Report). USGS Publications Warehouse. doi: 10.3133/ofr93322

Pratt, T. L. (2003). Amplification of Seismic Waves by the Seattle Basin, Washington State. Bulletin of the Seismological Society of America, 93(2), 533-545. doi: $\underline{10.1785 / 0120010292}$

R. Fernández-Ruiz, M., Costa, L., \& F. Martins, H. (2019). Distributed Acoustic Sensing Using Chirped-Pulse Phase-Sensitive OTDR Technology. Sensors, 19(20), 4368. doi: 10.3390/s19204368

Rost, S. (2002). Array seismology: Methods and applications. Reviews of Geophysics, 40(3). doi: $10.1029 / 2000 R G 000100$

Sladen, A., Rivet, D., Ampuero, J. P., De Barros, L., Hello, Y., Calbris, G., \& Lamare, P. (2019). Distributed sensing of earthquakes and ocean-solid Earth interactions on seafloor telecom cables. Nature Communications, 191), 1-8. doi: 10.1038/s41467$\underline{019-13793-z}$ 
manuscript submitted to Journal of Geophysical Research: Solid Earth

742 Vallée, M., Ampuero, J. P., Juhel, K., Bernard, P., Montagner, J.-P., \& Barsuglia, M. (2017).

743

744

745

746

747

748

749

750

751 Observations and modeling of the elastogravity signals preceding direct seismic waves. Science, 358(6367), 1164-1168. doi: 10.1126/science.aao0746

Williams, E. F., Fernández-Ruiz, M. R., Magalhaes, R., Vanthillo, R., Zhan, Z., GonzálezHerráez, M., \& Martins, H. F. (2019). Distributed sensing of microseisms and teleseisms with submarine dark fibers. Nature Communications, 10(1), 5778. doi: 10.1038/s41467-019-13262-7

Zhan, Z. (2020). Distributed Acoustic Sensing Turns Fiber-Optic Cables into Sensitive Seismic Antennas. Seismological Research Letters, 91(1), 1-15. doi: $\underline{10.1785 / 0220190112}$ 
manuscript submitted to Journal of Geophysical Research: Solid Earth

752 Supplementary figure captions

753 Figure S1: Average PSD sections for MEUST at different frequencies between

7544 and $9 \mathrm{~km}$ from the interrogator.

755

756

757

Figure S2: As in figure 4 for a M2 earthquake at approximately $30 \mathrm{~km}$ recorded by NESTOR.

758

759

Figure S3: As in figure 4 for a M2.6 earthquake at approximately $166 \mathrm{~km}$

760 recorded by MEUST.

761

762

Figure S4: As in figure 5 for 4 earthquakes recorded by NESTOR between

763 19.7 and $20.2 \mathrm{~km}$ from the interrogator.

764

765

Figure S5: As in figures 5 (top) and 6 (bottom) for 2 earthquakes recorded by

766

767

768

769

770

771

772

773

774

775

776

777

778

779 HCMR between 6 and $6.3 \mathrm{~km}$ from the interrogator.

Figure S6: As in figures 5 (top) and 6 (bottom) for 2 earthquakes recorded by HCMR between 0.5 and $1.5 \mathrm{~km}$ from the interrogator.

Figure S7: As in figures 5 (top) and 8 (bottom) for 2 earthquakes recorded by MEUST between 29.7 and $30.7 \mathrm{~km}$ from the interrogator.

Figure S8: As in figures 5 (top) and 8 (bottom) for 2 earthquakes recorded by MEUST between 12.2 and $12.6 \mathrm{~km}$ from the interrogator.

Figure S9: As in figures 5 (top) and 8 (bottom) for 2 earthquakes recorded by HCMR between 2.3 and $2.85 \mathrm{~km}$ from the interrogator. The earthquake in top panels is detected while that in the bottom panels is not detected. 